\title{
A novel risk model for mortality and hospitalization following cardiac resynchronization therapy in patients with non-ischemic cardiomyopathy: the alpha- score
}

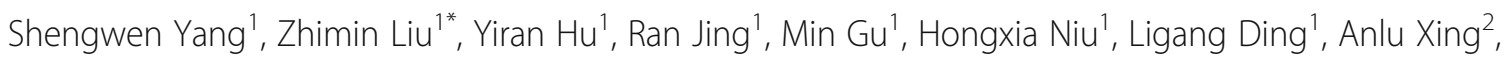
Shu Zhang ${ }^{1}$ and Wei Hua ${ }^{*}$

\begin{abstract}
Background: Non-ischemic cardiomyopathy (NICM) has been associated with a better left ventricle reverse remodeling response and improved clinical outcomes after cardiac resynchronization therapy (CRT). The aims of our study were to identify the predictors of mortality and heart failure hospitalization in patients treated with CRT and design a risk score for prognosis.

Methods: A cohort of 422 consecutive NICM patients with CRT was retrospectively enrolled between January 2010 and December 2017. The primary endpoint was all-cause mortality and heart transplantation.

Results: In a multivariate analysis, the predictors of all-cause death were left atrial diameter [Hazard ratio (HR): 1.056, 95\% confidence interval (Cl): 1.020-1.093, $P=0.002$ ]; non-left bundle branch block [HR: 1.793, 95\% Cl: 1.131-2.844, $P=0.013]$; high sensitivity C-reactive protein [HR: 1.081, 95\% Cl: 1.029-1.134 $P=0.002$ ]; and N-terminal pro-B-type natriuretic peptide [HR: 1.018, 95\% Cl: 1.007-1.030, $P=0.002]$; and New York Heart Association class IV [HR: 1.018, 95\% Cl: 1.007-1.030, $P=0.002$ ]. The Alpha-score (Atrial diameter, non-LBBB, Pro-BNP, Hs-CRP, NYHA class IV) was derived from each independent risk factor. The novel score had good calibration (Hosmer-Lemeshow test, $P>0.05$ ) and discrimination for both primary endpoints [C-statistics: 0.749 (95\% Cl: 0.694-0.804), $P<0.001$ ] or heart failure hospitalization [c-statistics: 0.692 (95\% Cl: 0.639-0.745), $P<0.001$ ].
\end{abstract}

Conclusion: The Alpha-score may enable improved discrimination and accurate prediction of long-term outcomes among NICM patients with CRT.

Keywords: Non-ischemic cardiomyopathy, Heart failure, Risk model, Hosmer-Lemeshow test

\footnotetext{
*Correspondence: liucory@163.com; drhuaweifw@sina.com

'State Key Laboratory of Cardiovascular Disease, Fuwai Hospital, National Center for Cardiovascular Diseases, Chinese Academy of Medical Sciences and Peking Union Medical College, No.167 Beilishi Road, Xicheng District, Beijing 100037, China

Full list of author information is available at the end of the article
}

(c) The Author(s). 2020 Open Access This article is licensed under a Creative Commons Attribution 4.0 International License, which permits use, sharing, adaptation, distribution and reproduction in any medium or format, as long as you give appropriate credit to the original author(s) and the source, provide a link to the Creative Commons licence, and indicate if changes were made. The images or other third party material in this article are included in the article's Creative Commons licence, unless indicated otherwise in a credit line to the material. If material is not included in the article's Creative Commons licence and your intended use is not permitted by statutory regulation or exceeds the permitted use, you will need to obtain permission directly from the copyright holder. To view a copy of this licence, visit http://creativecommons.org/licenses/by/4.0/ The Creative Commons Public Domain Dedication waiver (http://creativecommons.org/publicdomain/zero/1.0/) applies to the data made available in this article, unless otherwise stated in a credit line to the data. 


\section{Background}

Cardiac resynchronization therapy (CRT) improves cardiac function and decreases hospital admissions and mortality among patients with advanced heart failure (HF) and left ventricular dyssynchrony [1-3]. However, based on data derived from numerous large-sample, randomized trials, approximately one-third of all CRT recipients fail to achieve the expected benefit from the device [4]. Since the implantation of CRT devices is an invasive approach with a relatively high the economic burden, the application of a risk model for candidate stratification could aide in the optimal selection of patients and in identifying eligible patients likely to receive the greatest benefit. Non-ischemic cardiomyopathy (NICM) is one of the major causes of $\mathrm{HF}$, especially in Asia [5, 6]. Given that patients with NICM have distinctive pathophysiology compared to that of ischemic patients, their predictors could be different from the that of published models, and the weight of the values for similar predictors may be distinct [7]. Multiple studies have attempted to combine various clinical and biomarker metrics into a risk score to predict the prognosis [8-11]. However, to our knowledge, a predictive risk model for long-term outcomes focused on NICM patients with CRT is lacking.

Therefore, our study focused on (i) investigating the independent predictors of all-cause mortality and heart transplantation or HF in NICM patients treated with CRT; (ii) developing a new risk model for stratifying NICM CRT candidates and assessing its performance for all-cause mortality, heart transplantation, and $\mathrm{HF}$ hospitalization in NICM.

\section{Methods}

\section{Study population}

We enrolled 459 consecutive patients with CRT in the Arrhythmia Center of Fuwai Hospital between January 2010 and December 2017.

Diagnosis of NICM patients was made according to classification by the cardiomyopathies' criteria [12], defined as the presence of systolic dysfunction without a history of myocardial infarction and/or the absence of significant coronary artery disease documented on a coronary angiogram. Inclusion criteria were in accordance with guidelines for cardiac resynchronization and defibrillation [13]: symptomatic HF, left ventricle (LV) ejection fraction $<35 \%$ and QRS exhibiting left bundle branch lock with a duration $\geq 120 \mathrm{~ms}$. All patients received optimal medical therapy for at least 3 months prior to CRT implantation. Patients were excluded if they (1) were aged < 18 years, (2) were pregnant, (3) had prior pacemakers or implantable cardioverter defibrillator implantation, (4) were patients classified as a nonambulatory New York Heart Association (NYHA) class IV, or (5) lost to follow-up.

Ten candidates failed LV lead implantation; ten declined CRT implantation because of financial difficulties; three patients were excluded based on the exclusion criteria, and 14 patients were lost during follow-up. Finally, a total of 422 eligible NICM patients with CRT were enrolled (Fig. 1).

The Institutional Review Board of Fuwai Hospital approved the study, and all participants provided signed informed consent.

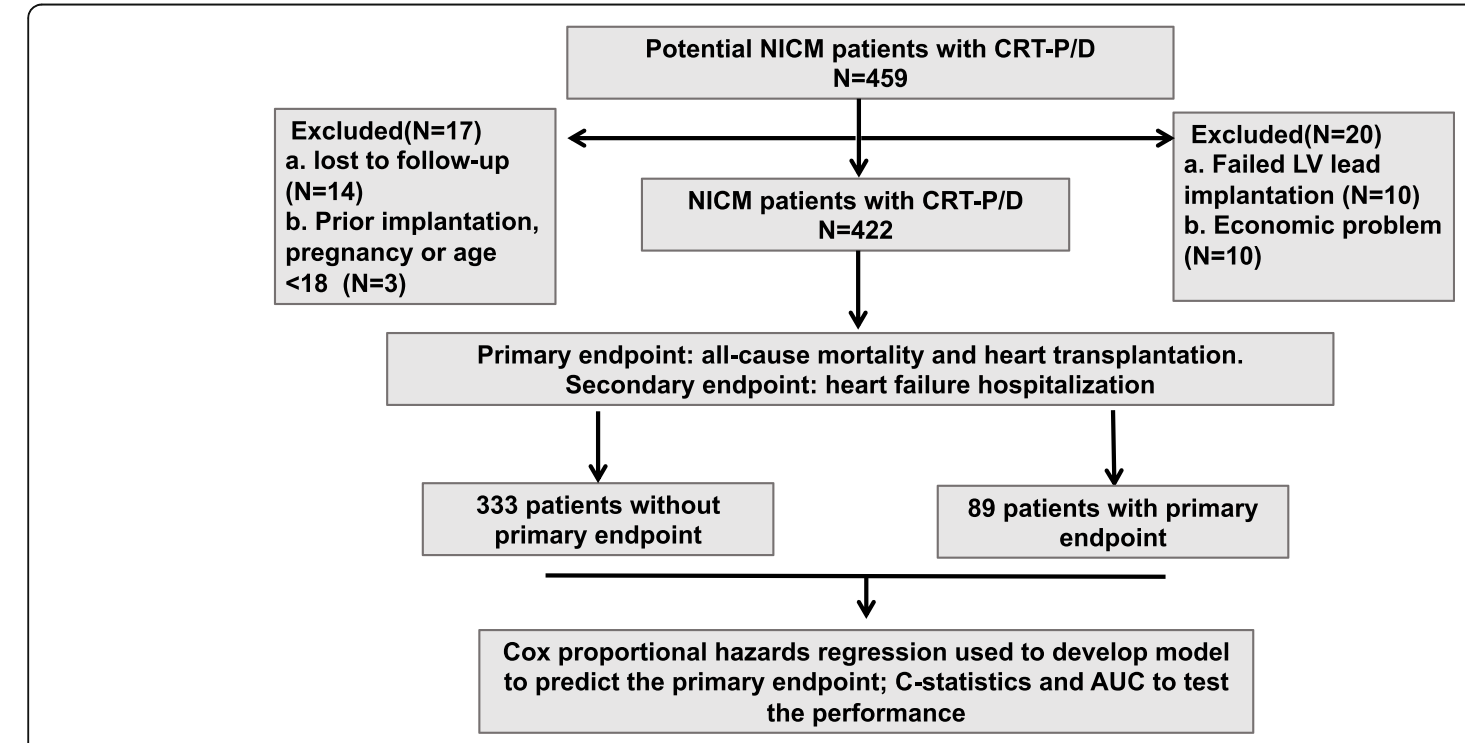

Fig. 1 A diagram to describe the flow of participants through the study 


\section{Device implantation}

All patients were implanted with a cardiac resynchronization therapy- pacemaker (CRT-P) or cardiac resynchronization therapy- defibrillator (CRT-D) according to contemporary clinical practice guidelines [13]. The inclusion criteria were: symptomatic HF, LV ejection fraction $<35 \%$ and QRS exhibiting left bundle branch lock with a duration $\geq 120 \mathrm{~ms}$. The leads of the LV were inserted into a lateral or posterolateral coronary sinus branch through the subclavian route. The interventricular and atrioventricular intervals were optimized by program ming on the day after implantation, which allowed maximizing the amount of $\mathrm{BiV}$ (as close to $95 \%$ as possible) by electrocardiography (ECG). All participants followed up with optimal programming and received standard medications for HF after implantation.

\section{Follow-up and study endpoints}

All patients underwent regular follow-up via outpatient clinical visits or telephone interviews. The primary endpoint of the study was all-cause mortality or heart transplantation. The secondary endpoint was hospitalization due to HF. If patients were hospitalized for HF more than once, only the first hospitalization was counted. Two independent physicians who were blinded to the patients' clinical data evaluated the endpoints.

\section{Statistical analysis}

Statistical analyses were performed using SPSS version 23 (IBM Corp, Chicago, IL). Continuous data are presented as the mean and standard deviation (SD), and categorical variables are presented as numbers and percentages. The Kolmogorov-Smirnov test was used to test the normality of the distribution of continuous variables. Student's t-test, nonparametric equivalent tests and chisquare tests were utilized as appropriate. For N-terminal pro-B-type natriuretic peptide (NT pro-BNP), pg/100 ml was used as its unit of measurement. The Kaplan-Meier method was used to construct survival curve with a logrank test according to the different scores and risk groups. Adjusted hazard ratios were calculated by Cox regression analysis after correcting for differences in baseline characteristics. Variables with a bootstrapped $P<0.05$ were assigned a weighted point score based on their associated hazard ratio and a simple score was calculated via the addition of all the points. The optimal cutoff point was detected by identifying the Youden index point (sensitivity + specificity -1 ). The area under the receiver-operating characteristic curve (AUC) or $\mathrm{c}$ statistic to assess the discrimination in receiver operating characteristic (ROC) curves. The calibration of the score was assessed by the Hosmer-Lemeshow test. The AUC ranged from 0.5 (no discrimination) to 1.0 (perfect discrimination). Two-sided $p$ values $<0.05$ were considered statistically significant.

\section{Results \\ Baseline characteristics}

Table 1 lists the baseline characteristics of the study population. The study cohort was comprised of 422 consecutively enrolled NICM patients implanted with CRTD or CRT-P devices. The mean age of the patients was $59 \pm 11$ years; $64.7 \%(273 / 422)$ were male; $43.4 \%(183 /$ 422) were implanted with CRT-D, and 70.4\% (297/422) exhibited a left bundle branch block (LBBB) on an ECG. During a median follow-up period of 22.82 months (12.17-37.20 months), 89 primary endpoints events occurred: 81 deaths, 10 heart transplantations (including two patients who died after the heart transplantation). There was a total of 113 patients with hospitalizations for HF. Compared with patients without primary endpoint events, patients with primary endpoint events had lower left ventricular ejection fraction (LVEF), higher NT Pro-BNP level, and a decreased use of Angiotensin converting enzyme inhibitors (ACEIs) or angiotensin receptor blockers (ARB) in patients with events; however, there were no statistically statistical differences in age, sex, CRT type, or prevalence of atrial fibrillation at baseline between the two groups.

Independent predictors of the primary endpoint from the derivation dataset

In the multivariable analysis (Table 2), five independent predictors were associated with the risk of the primary endpoint: left atrium (LA) diameter [Hazard ratio (HR): 1.056, 95\% confidence interval (CI): 1.020-1.093, $P=$ 0.002]; non-LBBB [HR: $1.793,95 \% \mathrm{CI}: 1.131-2.844, P=$ 0.013 ] high sensitivity $C$-reactive protein (HsCRP) [HR: 1.081, 95\% CI: $1.029-1.134 P=0.002]$; and NT Pro-BNP [HR: 1.018, 95\% CI: 1.007-1.030, $P=0.002$ ]; and New York Heart Association (NYHA) class IV [HR: 1.018, 95\% CI: 1.007-1.030, $P=0.002$ ].

We used these five independent predictors: Atrial diameter, non-LBBB, Pro-BNP, Hs-CRP, NYHA class IV, to develop the Alpha. Each categorical predictor was assigned 1 point individually. For the continuous parameters, the cutoff points were evaluated by the Youden index point. (Table 3). Score-tertiles were created according to the tertile of the Alpha score ( $0-1$ point as the low-risk group; $2-3$ points as the intermediate-risk group, and 4-5 points as the high-risk group).

\section{Performance of the alpha-score}

As shown in Figs. 2 and 3, the risk of poor outcomes increased with the accumulation of risk factors. KaplanMeier survival estimates, according to the Alpha scores and different risk groups for the primary endpoint and 
Table 1 Baseline characteristics

\begin{tabular}{|c|c|c|c|c|}
\hline Variables & $\begin{array}{l}\text { Overall } \\
N=422\end{array}$ & $\begin{array}{l}\text { Patients with primary endpoint events } \\
N=333\end{array}$ & $\begin{array}{l}\text { Patients without primary endpoint events } \\
N=89\end{array}$ & $P$-value \\
\hline$\overline{\text { Age, } y}$ & $59 \pm 11$ & $59 \pm 11$ & $58 \pm 12$ & 0.989 \\
\hline Male, n (\%) & $273(64.7)$ & $208(62.5)$ & 65(73.0) & 0.064 \\
\hline CRT-D, n (\%) & 183(43.4) & 138(41.4) & 45(50.6) & 0.123 \\
\hline BMI, $\left(\mathrm{kg} / \mathrm{m}^{2}\right)$ & $24.53 \pm 4.71$ & $24.85 \pm 4.93$ & $2323 \pm 3.46$ & 0.006 \\
\hline Atrial fibrillation, n (\%) & $71(16.8)$ & $50(15.0)$ & 21(23.6) & 0.055 \\
\hline LBBB, n (\%) & 297(70.4) & $250(75.1)$ & $47(52.8)$ & $<0.001$ \\
\hline \multicolumn{5}{|l|}{ NYHA class, n (\%) } \\
\hline ॥ & $128(30.3)$ & 113(33.9) & $15(16.9)$ & 0.002 \\
\hline III & $239(56.6)$ & $187(56.2)$ & $52(58.4)$ & 0.701 \\
\hline IV & $55(13)$ & $33(9.9)$ & $22(24.7)$ & $<0.001$ \\
\hline Initial QRS width(ms) & $166.92 \pm 22.58$ & $164.43 \pm 23.44$ & $168.81 \pm 19.03$ & 0.065 \\
\hline \multicolumn{5}{|l|}{ Echocardiography } \\
\hline $\mathrm{LA}(\mathrm{mm})$ & $44.14 \pm 7.41$ & $43.38 \pm 7.19$ & $47.00 \pm 7.54$ & $<0.001$ \\
\hline $\operatorname{LVEDD}(\mathrm{mm})$ & $70.09 \pm 10.69$ & $69.34 \pm 10.62$ & $72.91 \pm 10.52$ & 0.005 \\
\hline LVEF (\%) & $30.45 \pm 8.45$ & $30.95 \pm 8.53$ & $28.60 \pm 7.91$ & 0.020 \\
\hline \multicolumn{5}{|l|}{ Laboratory factors } \\
\hline NT-proBNP (pg/ml) & $2173 \pm 2018$ & $1912 \pm 1798$ & $3150 \pm 2462$ & $<0.001$ \\
\hline Uric Acid (umol/L) & $433.65 \pm 130.00$ & $430.15 \pm 124.65$ & $446.75 \pm 148.35$ & 0.285 \\
\hline $\mathrm{HsCRP}(\mathrm{mg} / \mathrm{L})$ & $2.79 \pm 3.89$ & $3.21 \pm 3.48$ & $5.67 \pm 4.69$ & $<0.001$ \\
\hline Creatinine(umol/L) & $90.98 \pm 28.69$ & $88.65 \pm 23.66$ & $99.68 \pm 41.57$ & 0.001 \\
\hline Albumin & $42.13 \pm 4.87$ & $42.62 \pm 4.94$ & $40.31 \pm 4.15$ & $<0.001$ \\
\hline AST & $23.41 \pm 11.88$ & $22.56 \pm 10.97$ & $26.55 \pm 14.42$ & 0.005 \\
\hline Big endothelin-1 & $0.55 \pm 0.41$ & $0.49 \pm 0.37$ & $0.78 \pm 0.45$ & $<0.001$ \\
\hline \multicolumn{5}{|l|}{ Medications } \\
\hline ACEI/ARB, n (\%) & $330(78.2)$ & $273(82.0)$ & $57(64.0)$ & $<0.001$ \\
\hline Beta-blockers, n (\%) & 384(91) & 304(91.3) & $80(89.9)$ & 0.681 \\
\hline Diuretics, n (\%) & 396(93.8) & $313(94.0)$ & 83(93.3) & 0.798 \\
\hline Spironolactone, n (\%) & $373(88.4)$ & 299(89.8) & 74(83.1) & 0.082 \\
\hline
\end{tabular}

CRT-D cardiac resynchronization therapy with a defibrillator, BMI Body mass index, LBBB Left bundle branch block, RBBB Right bundle branch block, NYHA The New York Heart Association Functional Classification, LA Left atrial dimeters, LVEDD Left ventricular end diastolic diameter, LVEF Left ventricular ejection fraction, NTproBNP N-terminal pro-B-type natriuretic peptide, HsCRP High-sensitivity C-reactive protein, LDL-C Low density lipoprotein cholesterol, HDL-C High density lipoprotein cholesterol, AST Aspartate aminotransferase, $A C E I$ Angiotensin converting enzyme inhibitor, ARB Angiotensin receptor blockers; $P$-value:Comparison between derivation cohort and validation cohort

HF hospitalization. Notably, based on the Alpha-score system, the rate of HF hospitalization among patients with higher scores was significantly higher than those with lower scores.

The c statistics of the model were 0.749 (95\% CI: 0.694$0.804, P<0.001)$ for the primary endpoint and $0.692(95 \%$ CI: $0.639-0.745, P<0.001$ ) for HF hospitalization. (Fig. 4).

\section{Discussion}

\section{Importance of the new score}

This large, observational study first derived a long-term prognosis model for NICM HF patients implanted with CRT. The Alpha-score was based on the largest retrospective cohort of Chinese NICM patients with CRT.
The risk score performed well in predicting the long-term prognosis of NICM patients based on clinical characteristics and biomarkers; it showed a good predictive ability for both all-cause mortality and HF hospitalization within the derivation and validation datasets. The Alpha score, as a simple and easy-to-use score, could be used for clinical risk stratification before CRT implantation and long-term follow-up.

\section{The published scores}

Over the past decades, prior risk models $[9,10,14-16]$ were derived with good calibration and accuracy in derivation cohorts or Western validation cohorts; however, Asian populations, especially Chinese participants, are 
Table 2 Predictors of all-cause mortality and heart transplantation risk by uni- and multivariate Cox proportional hazards

\begin{tabular}{|c|c|c|c|c|}
\hline \multirow[t]{2}{*}{ Variables } & \multicolumn{2}{|l|}{ Univariate } & \multicolumn{2}{|l|}{ Multivariate } \\
\hline & $\mathrm{HR}(95 \% \mathrm{Cl})$ & $P$-value & $\mathrm{HR}(95 \% \mathrm{Cl})$ & $P$-value \\
\hline Age & $0.996(0.977-1.015)$ & 0.667 & & \\
\hline gender(male) & $1.715(1.072-2.743)$ & 0.024 & & \\
\hline Non-LBBB & $2.142(1.412-3.248)$ & $<0.001$ & $1.718(1.128-2.616)$ & 0.012 \\
\hline Type of device (CRT-D) & $1.489(0.980-2.260)$ & 0.062 & & \\
\hline Atrial Fibrillation & $1.748(1.070-2.858)$ & 0.026 & & \\
\hline NYHA function class IV & $2.356(1.455-3.817)$ & $<0.001$ & $1.663(1.020-2.712)$ & 0.042 \\
\hline AST & $1.018(1.005-1.030)$ & 0.005 & & \\
\hline HS-CRP & 1.107(1.060-1.156) & $<0.001$ & $1.065(1.018-1.114)$ & 0.006 \\
\hline NT-proBNP per100 & $1.029(1.021-1.037)$ & $<0.001$ & $1.018(1.008-1.029)$ & $<0.001$ \\
\hline Big Endothelin-1 & $1.778(1.256-2.515)$ & $<0.001$ & & \\
\hline $\begin{array}{l}\text { Creatinine } \\
\text { Uric acid }\end{array}$ & $\begin{array}{l}1.008(1.003-1.013) \\
1.001(1.000-1.003)\end{array}$ & $\begin{array}{l}0.002 \\
0.063\end{array}$ & & \\
\hline LA & $1.085(1.054-1.116)$ & $<0.001$ & $1.052(1.018-1.087)$ & 0.002 \\
\hline LVEDD & $1.029(1.010-1.048)$ & 0.003 & & \\
\hline
\end{tabular}

Abbreviations as Table 1

rarely used for validation [17]. VALID-CRT [11]and sex category, renal function, ECG/QRS width, ejection fraction, and NYHA class (ScREEN) [8] scores were derived and validated in European multicenter studies, and ejection fraction, atrial fibrillation, age, renal function, and NYHA class (EARRN) [10] does not have a validation population.

The prevalence of ischemic HF in CRT candidates was greater than $50 \%$ in most studies $[1,7,9,10,18]$ conducted in North America and Europe. However, the situation in Asia is significantly different with regards to the subtype of CRT candidates [19-21]. Based on the Japan Cardiac Device Treatment Registry (JCDTR) database [21], the proportion of HF patients with NICM is as great as $70 \%$. Based on our previous studies, patients with NICM were also common (>60\%)in China [6, 22].

Studies have shown that patients with a non-ischemic etiology have a better prognosis than patients with an ischemic etiology. With a lower myocardial fibrosis scar fibrosis scar burden, NICM has the favorable reverse remodeling rather than ICM, which may be a possible

Table 3 The Alpha score standards

\begin{tabular}{lll}
\hline Letter & Risk factor & Score (if present) \\
\hline A & Left atrial diameter $(>44.5 \mathrm{~cm})$ & 1 \\
$\mathrm{~L}$ & non-left bundle branch block & 1 \\
$\mathrm{P}$ & $\begin{array}{l}\text { N-terminal pro-B-type natriuretic } \\
\text { peptide }(>13.53 \text { per } 100 \mathrm{pg} / \mathrm{ml})\end{array}$ & 1 \\
& $\begin{array}{l}\text { high sensitivity C-reactive protein } \\
\text { H }\end{array}$ & 1 \\
A & NYHA IV & 1 \\
Max score & & 5 \\
\hline
\end{tabular}

mechanism [23, 24].. Thus, various physiological mechanisms may lead to different pathophysiology, clinical status, and response to device therapy. The distinct physiological mechanisms between NICM and ICM could lead to different pathophysiology, clinical status and responses to device therapy. This was a negligible but significant reason for poor discrimination in many of the predictive models among CRT patients. The performance of risk models based on the Western population might be modest in NICM patients with CRT; These scores are readily available to clinicians as they are based on common clinical risk factors, although, it is suggested that recalibration based on different etiologies might improve the applicability of the scores for the NICM population.

\section{Variables associated with the risk of all-cause mortality and heart failure exacerbation}

The five identified baseline covariates in the Alpha score are aligned with those identified in previous studies. Several earlier studies reported that inflammation and heart functional biomarkers were associated with HF outcomes. It is known that inflammation plays an important role in the pathogenesis and progression of heart failure $[9,25]$. HsCRP, one of the circulating biomarkers of inflammation related to the severity of heart failure, is a sensitive predictor and is widely used to evaluate clinical outcomes [9, 26, 27]. Chi Cai, et al. [19] indicated that an elevated baseline level of HsCRP level was an independent predictor of adverse survival and increased HF hospitalization. In contrast, other studies [28], with relatively small sample sizes, have shown that baseline levels of HsCRP were not associated with long-term outcomes, and the sample size of those studies is relatively small. 


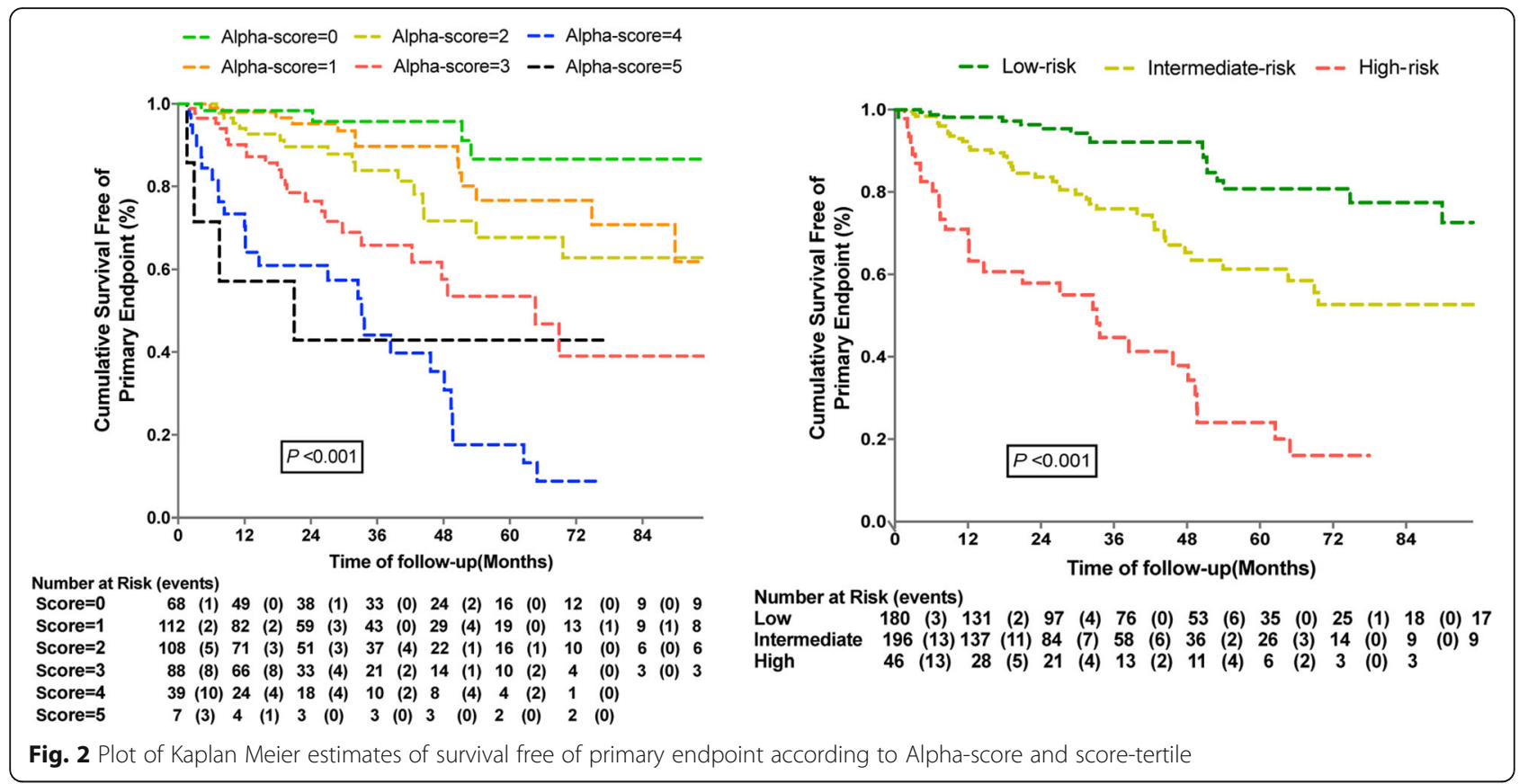

As a marker of ventricle dysfunction, the plasma NT pro-BNP level is a comprehensive index of cardiac function with high sensitivity and specificity. Similarly, in our study, elevated NT pro-BNP levels were an independent predictor of HF progression and mortality, which is consistent with several earlier studies $[16,29,30]$.

The LBBB was traditionally a strong predictor of electrical LV discordance in numerous large trials $[7$, 31-34]. Our results are consistent with the findings of the MADIT-CRT [7], RAFT [35], and REVERSERS [36] trials, which have been shown that non-LBBB patients have an increased rate of mortality due to CRT compared to those with LBBB. A meta-analysis of the major CRT trials also confirmed that a greater benefit from the devices was found when a LBBB morphology was present in patients who underwent CRT, which is strongly recommended for symptomatic HF patients in current guidelines.

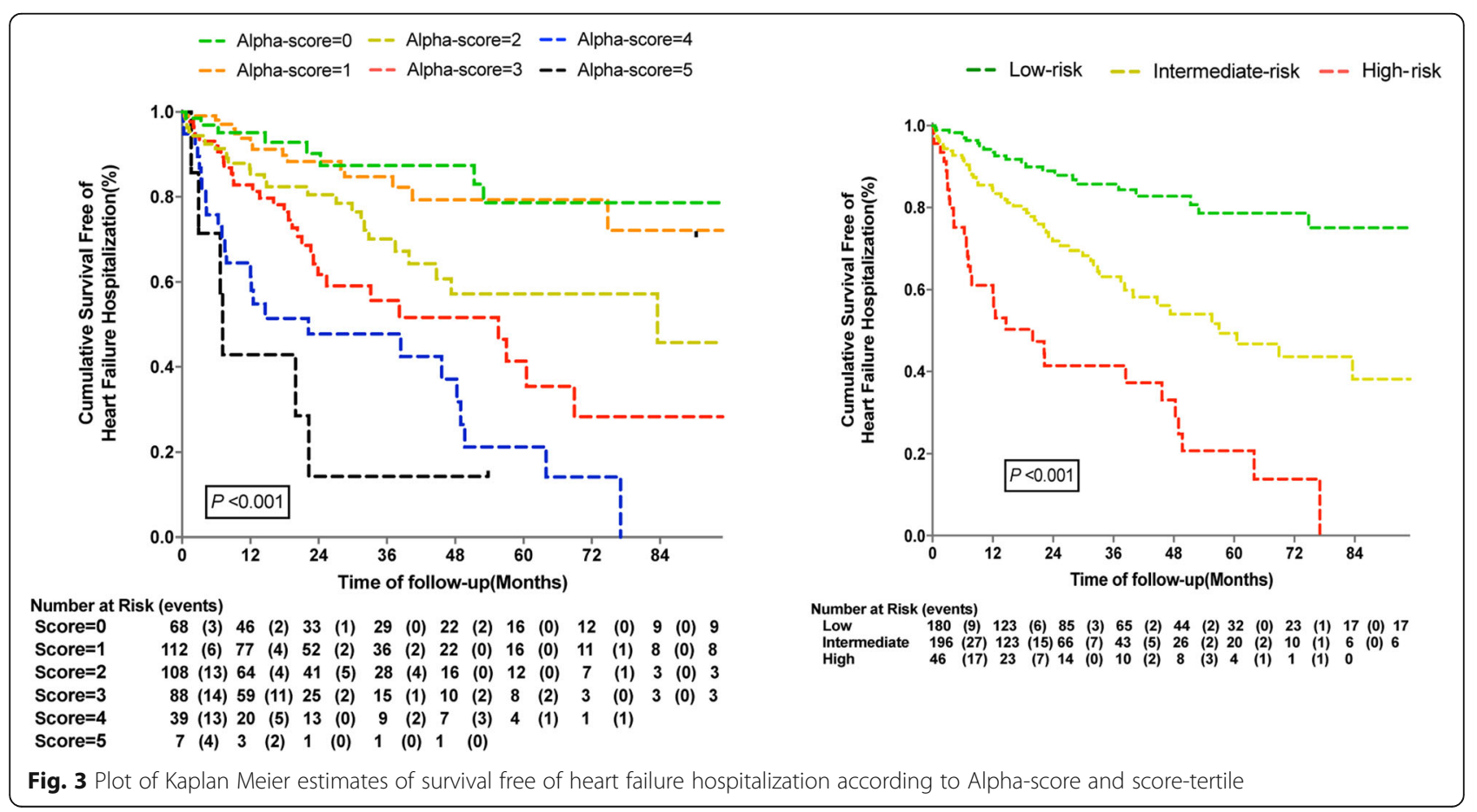




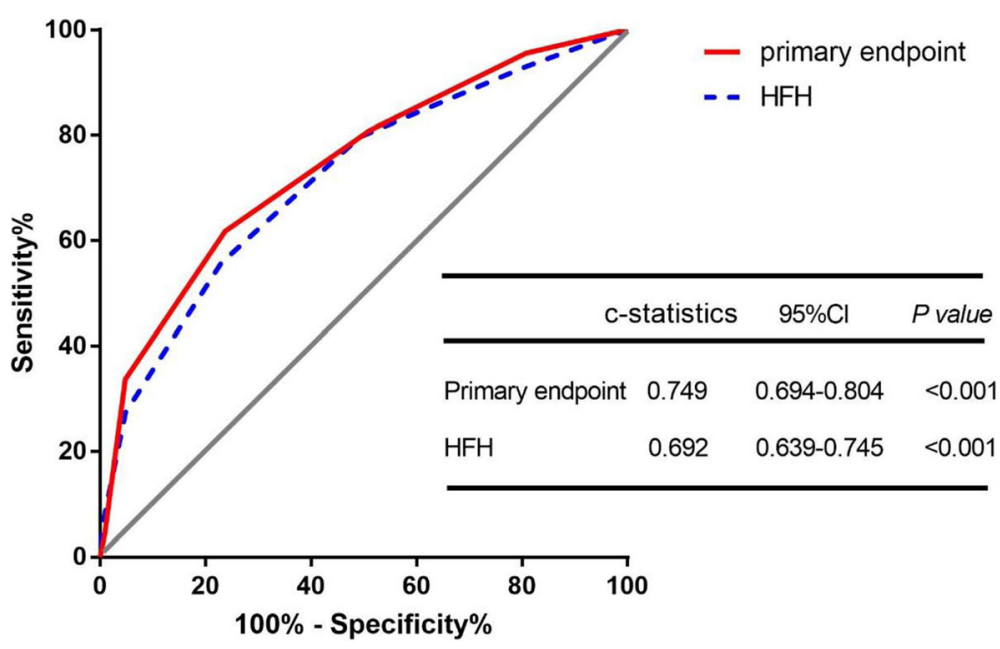

Fig. 4 Comparison of area under the curve for Alpha-score of all-cause death and heart transplantation among overall 422 NICM patients with CRT

The LA, as a reservoir for blood and a contractile chamber, important in LV filling, plays small but significant role in circulation. The size of the LA has been suggested as an independent factor for adverse cardiovascular events in multiple previous studies, especially among HF patients [37-39]. When atrial fibrillation occurs, patients who have undergone CRT not only lose approximately $25 \%$ of diastolic blood filling but also suffer from decreased biventricular pacing due to the rapid atrial rate and variability of atrioventricular conduction time. Some studies suggest that the duration of atrial fibrillation, rather than atrial fibrillation itself, is associated with prognosis $[31,40]$. In our study, atrial fibrillation included paroxysmal atrial fibrillation and persistent atrial fibrillation. In this study, considering these factors, atrial size is a more reliable indicator of LA function. Although the mechanism remains uncertain, the larger LA size is associated with pulmonary hemodynamic alterations and LA dilatation and dysfunction [7, 34, 39, 41, 42].

Some studies suggest that patient characteristics, such as severity of mitral insufficiency, renal failure, baseline LVEF and age, are risk factors for poor prognosis in patients receiving CRT $[9,16,42]$. However, there are not enough data to prove that these variables are independent predictors in NICM patients.

\section{Limitations of our study}

This study has some limitations. First, as it is an observational, retrospective study. The baseline characteristics were retrieved from Fuwai Hospital's medical records, and we had no data on serial measurements of biomarkers and ECG parameters. Therefore, our results may not provide model prediction values for the CRT response. Second, the proportion of CRT-D patients in the validation dataset was relatively small, and the patient composition might limit the applicability of the Alpha score in all CRT recipients. Third, data on the final LV lead location, cardiac magnetic resonance imaging for scar tissue and QRS duration after implantation were not collected prospectively. Finally, although the validation dataset was selected randomly in our cohort and determination was good, the potential clinical utility of the Alpha model for risk stratification requires a larger population and further investigation. Despite these limitations, this is the first and largest risk model for NICM patients with CRT in Asia. We believe that the Alpha score could provide useful prognostic information on NICM among CRT recipients.

\section{Conclusions}

In CRT candidates without ICM, atrial diameter, nonLBBB, Pro-BNP, Hs-CRP, NYHA class IV are associated with all-cause mortality and HF transplantation, which could provide a readily available tool for identifying patients who require intensive monitoring and for effective prediction of long-term outcomes among NICM patients who are potential recipients of CRT.

\section{Abbreviations}

NICM: Non-ischemic cardiomyopathy; CRT: Cardiac resynchronization therapy; HR: Hazard ratio; Cl: Confidence interval; HF: Heart failure; LV: Left ventricle; NYHA: New York heart association; CRT-P: Cardiac resynchronization therapy pacemaker; CRT-D: Cardiac resynchronization therapy defibrillator; ECG: Electrocardiography; NT pro-BNP: N-terminal pro-brain natriuretic peptide; AUC: The area under the receiver-operating characteristic curve; ROC: Receiver operating characteristic; LBBB: Left bundle branch block; LVEF: Left ventricular ejection fraction; ACEl: Angiotensin converting enzyme inhibitors; ARB: Angiotensin receptor blockers; LA: Left atrium; HsCRP: High sensitivity C-reactive protein; JCDTR: Japan cardiac device treatment registry; ICM: Ischemic cardiomyopathy; LDL-C: Low density lipoprotein cholesterol; HDL-C: High-density lipoprotein cholesterol; AST: Aspartate aminotransferase

Acknowledgements

None. 


\section{Authors' contributions}

WH and ZL contributed to the study conception and design. SY, YH and RJ performed material preparation, data collection and analysis. MG, HN, LD AX and SZ helped to perform the analysis with constructive discussions. The first draft of the manuscript was written by SY, and all authors commented on previous versions of the manuscript. All authors read and approved the final manuscript.

\section{Funding}

This work was supported by Chinese Academy of Medical Sciences Innovation Fund for Medical Sciences (2017-I2M-1-009) and National Natural Science Foundation of China (81570370).

\section{Availability of data and materials}

The datasets used and analyzed during the current study are available from the corresponding author on reasonable request.

\section{Ethics approval and consent to participate}

The experimental protocol was established, according to the ethical guidelines of the Helsinki Declaration and was approved by the Human Ethics Committee of Fuwai Hospital. Written informed consent was obtained from individual or guardian participants.

\section{Consent for publication}

Not applicable.

\section{Competing interests}

The authors declare that they have no competing interests.

\section{Author details}

'State Key Laboratory of Cardiovascular Disease, Fuwai Hospital, National Center for Cardiovascular Diseases, Chinese Academy of Medical Sciences and Peking Union Medical College, No.167 Beilishi Road, Xicheng District, Beijing 100037, China. ${ }^{2}$ Amazon, Palo alto, CA, USA.

Received: 13 June 2019 Accepted: 1 April 2020

Published online: 28 April 2020

\section{References}

1. Bristow MR, Saxon LA, Boehmer J, Krueger S, Kass DA, De Marco T, Carson P, DiCarlo L, DeMets D, White BG, et al. Cardiac-resynchronization therapy with or without an implantable defibrillator in advanced chronic heart failure. N Engl J Med. 2004;350(21):2140-50.

2. Cleland JG, Daubert JC, Erdmann E, Freemantle N, Gras D, Kappenberger L, Tavazzi L. Cardiac resynchronization-heart failure study I: the effect of cardiac resynchronization on morbidity and mortality in heart failure. N Engl J Med. 2005;352(15):1539-49.

3. Tang AS, Wells GA, Talajic M, Arnold MO, Sheldon R, Connolly S, Hohnloser SH, Nichol G, Birnie DH, Sapp JL, et al. Cardiac-resynchronization therapy for mild-to-moderate heart failure. N Engl J Med. 2010;363(25):2385-95.

4. Abraham WT, Fisher WG, Smith AL, Delurgio DB, Leon AR, Loh E, Kocovic DZ, Packer M, Clavell AL, Hayes DL, et al. Cardiac resynchronization in chronic heart failure. N Engl J Med. 2002;346(24):1845-53.

5. Yokoshiki H, Shimizu A, Mitsuhashi T, Furushima H, Sekiguchi Y, Manaka T, Nishii N, Ueyama T, Morita N, Okamura H, et al. Survival and heart failure hospitalization in patients with cardiac resynchronization therapy with or without a defibrillator for primary prevention in Japan- analysis of the Japan cardiac device treatment registry database. Circ J. 2017;81(12):1798-806.

6. Yang S, Liu Z, Liu S, Ding L, Chen K, Hua W, Zhang S. Association of baseline big endothelin-1 level with long-term prognosis among cardiac resynchronization therapy recipients. Clin Biochem. 2018:59:25-30.

7. Barsheshet A, Goldenberg I, Moss AJ, Eldar M, Huang DT, McNitt S, Klein HU, Hall WJ, Brown MW, Goldberger JJ, et al. Response to preventive cardiac resynchronization therapy in patients with ischaemic and nonischaemic cardiomyopathy in MADIT-CRT. Eur Heart J. 2011;32(13):1622-30.

8. Providencia R, Marijon E, Barra S, Reitan C, Breitenstein A, Defaye P, Papageorgiou N, Duehmke R, Winnik S, Ang R, et al. Usefulness of a clinical risk score to predict the response to cardiac resynchronization therapy. Int J Cardiol. 2018;260:82-7.

9. Nauffal V, Tanawuttiwat T, Zhang Y, Rickard J, Marine JE, Butcher B, Norgard S, Dickfeld T, Ellenbogen KA, Guallar E, et al. Predictors of mortality, LVAD implant, or heart transplant in primary prevention cardiac resynchronization therapy recipients: the HF-CRT score. Heart Rhythm. 2015;12(12):2387-94.

10. Khatib M, Tolosana JM, Trucco E, Borras R, Castel A, Berruezo A, Doltra A, Sitges M, Arbelo E, Matas M, et al. EAARN score, a predictive score for mortality in patients receiving cardiac resynchronization therapy based on pre-implantation risk factors. Eur J Heart Fail. 2014;16(7):802-9.

11. Gasparini M, Klersy C, Leclercq C, Lunati M, Landolina M, Auricchio A, Santini M, Boriani G, Proclemer A, Leyva F. Validation of a simple risk stratification tool for patients implanted with cardiac resynchronization therapy: the VALID-CRT risk score. Eur J Heart Fail. 2015;17(7):717-24.

12. Maron BJ, Towbin JA, Thiene G, Antzelevitch C, Corrado D, Arnett D, Moss AJ, Seidman CE, Young JB, American Heart A et al: Contemporary definitions and classification of the cardiomyopathies: an American Heart Association Scientific Statement from the Council on Clinical Cardiology, Heart Failure and Transplantation Committee; Quality of Care and Outcomes Research and Functional Genomics and Translational Biology Interdisciplinary Working Groups; and Council on Epidemiology and Prevention. Circulation 2006, 113 (14):1807-1816.

13. Brignole $M$, Auricchio $A$, Baron-Esquivias $G$, Bordachar $P$, Boriani $G$, Breithardt OA, Cleland J, Deharo JC, Delgado V, Elliott PM, et al. 2013 ESC guidelines on cardiac pacing and cardiac resynchronization therapy: the task force on cardiac pacing and resynchronization therapy of the European Society of Cardiology (ESC). Developed in collaboration with the European heart rhythm association (EHRA). Eur Heart J. 2013;34(29):2281-329.

14. Brunet-Bernard A, Marechaux S, Fauchier L, Guiot A, Fournet M, Reynaud A, Schnell F, Leclercq C, Mabo P, Donal E. Combined score using clinical, electrocardiographic, and echocardiographic parameters to predict left ventricular remodeling in patients having had cardiac resynchronization therapy six months earlier. Am J Cardiol. 2014;113(12):2045-51.

15. Kydd AC, Khan FZ, Ring L, Pugh PJ, Virdee MS, Dutka DP. Development of a multiparametric score to predict left ventricular remodelling and prognosis after cardiac resynchronization therapy. Eur J Heart Fail. 2014;16(11):1206-13.

16. Bakos Z, Chatterjee NC, Reitan C, Singh JP, Borgquist R. Prediction of clinical outcome in patients treated with cardiac resynchronization therapy - the role of NT-ProBNP and a combined response score. BMC Cardiovasc Disord. 2018;18(1):70.

17. Clemens M, Szegedi Z, Kardos L, Nagy-Balo E, Sandorfi G, Edes I, Csanadi Z. The Seattle heart failure model predicts survival in patients with cardiac resynchronization therapy: a validation study. J Card Fail. 2012;18(9):682-7.

18. Linde C, Abraham WT, Gold MR, Daubert C, Group RS. Cardiac resynchronization therapy in asymptomatic or mildly symptomatic heart failure patients in relation to etiology: results from the REVERSE (REsynchronization reVErses remodeling in systolic left vEntricular dysfunction) study. J Am Coll Cardiol. 2010;56(22):1826-31.

19. Cai C, Hua W, Ding LG, Wang J, Chen KP, Yang XW, Liu ZM, Zhang S. High sensitivity C-reactive protein and cardfiac resynchronization therapy in patients with advanced heart failure. J Geriatr Cardiol. 2014;11(4):296-302.

20. Rordorf R, Savastano S, Sanzo A, Spazzolini C, De Amici M, Camporotondo R, Ghio S, Vicentini A, Petracci B, De Regibus V, et al. Tumor necrosis factoralpha predicts response to cardiac resynchronization therapy in patients with chronic heart failure. Circ J. 2014;78(9):2232-9.

21. Yokoshiki H, Shimizu A, Mitsuhashi T, Furushima H, Sekiguchi Y, Manaka T, Nishii N, Ueyama T, Morita N, Nitta T, et al. Trends and determinant factors in the use of cardiac resynchronization therapy devices in Japan: analysis of the Japan cardiac device treatment registry database. J Arrhythm. 2016; 32(6):486-90.

22. Kang Y, Cheng L, Cui J, Li L, Qin S, Su Y, Mao J, Gong X, Chen H, Pan C, et al. A new score system for predicting response to cardiac resynchronization therapy. Cardiol J. 2015;22(2):179-87.

23. Bleeker GB, Kaandorp TA, Lamb HJ, Boersma E, Steendijk P, de Roos A, van der Wall EE, Schalij MJ, Bax JJ. Effect of posterolateral scar tissue on clinical and echocardiographic improvement after cardiac resynchronization therapy. Circulation. 2006;113(7):969-76.

24. Ypenburg C, Roes SD, Bleeker GB, Kaandorp TA, de Roos A, Schalij MJ, van der Wall EE, Bax JJ. Effect of total scar burden on contrast-enhanced magnetic resonance imaging on response to cardiac resynchronization therapy. Am J Cardiol. 2007;99(5):657-60.

25. Anand IS, Latini R, Florea VG, Kuskowski MA, Rector T, Masson S, Signorini S, Mocarelli P, Hester A, Glazer R, et al. C-reactive protein in heart failure: prognostic value and the effect of valsartan. Circulation. 2005;112(10):1428-34. 
26. Lamblin N, Mouquet F, Hennache B, Dagorn J, Susen S, Bauters C, de Groote P. High-sensitivity C-reactive protein: potential adjunct for risk stratification in patients with stable congestive heart failure. Eur Heart J. 2005;26(21):2245-50.

27. Kalogeropoulos AP, Tang WH, Hsu A, Felker GM, Hernandez AF, Troughton RW, Voors AA, Anker SD, Metra M, McMurray JJ, et al. High-sensitivity Creactive protein in acute heart failure: insights from the ASCEND-HF trial. J Card Fail. 2014;20(5):319-26.

28. Glick A, Michowitz Y, Keren G, George J. Neurohormonal and inflammatory markers as predictors of short-term outcome in patients with heart failure and cardiac resynchronization therapy. Isr Med Assoc J. 2006;8(6):391-5.

29. Sokal A, Lenarczyk R, Kowalski O, Mitrega K, Pluta S, Stabryla-Deska J, Streb W, Urbanik Z, Krzeminski TF, Kalarus Z. Prognostic value of collagen turnover biomarkers in cardiac resynchronization therapy: a subanalysis of the TRUST CRT randomized trial population. Heart Rhythm. 2016;13(5):1088-95.

30. Berger R, Shankar A, Fruhwald F, Fahrleitner-Pammer A, Freemantle N, Tavazzi L, Cleland JG, Pacher R. Relationships between cardiac resynchronization therapy and $\mathrm{N}$-terminal pro-brain natriuretic peptide in patients with heart failure and markers of cardiac dyssynchrony: an analysis from the cardiac resynchronization in heart failure (CARE-HF) study. Eur Heart J. 2009:30(17):2109-16.

31. Bilchick KC, Kamath S, DiMarco JP, Stukenborg GJ. Bundle-branch block morphology and other predictors of outcome after cardiac resynchronization therapy in Medicare patients. Circulation. 2010;122(20): 2022-30.

32. Shen X, Aronow WS, Holmberg MJ, Li H, Nair CK, Korlakunta H, Esterbrooks DJ. Cardiac resynchronization therapy in patients with intrinsic and right ventricular pacing-induced left bundle branch block pattern. Am J Ther. 2009;16(6):e44-50.

33. Mascioli G, Padeletti L, Sassone B, Zecchin M, Lucca E, Sacchi S, Boggian G, Tondo AL, Belvito C, Bakhtadze N, et al. Electrocardiographic criteria of true left bundle branch block: a simple sign to predict a better clinical and instrumental response to CRT. Pacing Clin Electrophysiol. 2012;35(8):927-34.

34. Shen X, Nair CK, Aronow WS, Hee T, Pasupuleti S, Holmberg MJ, Wang F, Esterbrooks DJ. A patient selection score for cardiac resynchronization therapy. Echocardiography. 2011;28(2):188-95.

35. Essebag V, Joza J, Birnie DH, Sapp JL, Sterns LD, Philippon F, Yee R, Crystal E, Kus T, Rinne $C$, et al. Incidence, predictors, and procedural results of upgrade to resynchronization therapy: the RAFT upgrade substudy. Circ Arrhythm Electrophysiol. 2015;8(1):152-8.

36. Gold MR, Padhiar A, Mealing S, Sidhu MK, Tsintzos SI, Abraham WT. Economic value and cost-effectiveness of cardiac resynchronization therapy among patients with mild heart failure: projections from the REVERSE longterm follow-up. JACC Heart Fail. 2017;5(3):204-12.

37. De Rosa R, Murray MI, Schranz D, Mas-Peiro S, Esmaeili A, Zeiher AM, Fichtlscherer S, Vasa-Nicotera M. Short-term decrease of left atrial size predicts clinical outcome in patients with severe aortic stenosis undergoing TAVR. Catheter Cardiovasc Interv. 2019.

38. Takx RAP, Vliegenthart R, Schoepf UJ, Nance JW, Bamberg F, Abro JA, Carr CM, Litwin SE, Apfaltrer P. Prognostic value of CT-derived left atrial and left ventricular measures in patients with acute chest pain. Eur J Radiol. 2017;86:163-8.

39. Modin D, Sengelov M, Jorgensen PG, Olsen FJ, Bruun NE, Fritz-Hansen T, Andersen DM, Jensen JS, Biering-Sorensen T. Prognostic value of left atrial functional measures in heart failure with reduced ejection fraction. J Card Fail. 2018.

40. Leong DP, Hoke U, Delgado V, Auger D, Witkowski T, Thijssen J, van Erven L, Bax JJ, Schalij MJ, Marsan NA. Right ventricular function and survival following cardiac resynchronisation therapy. Heart. 2013;99(10):722-8.

41. Hsu JC, Solomon SD, Bourgoun M, MCNitt S, Goldenberg I, Klein H, Moss AJ, Foster E, Committee M-CE. Predictors of super-response to cardiac resynchronization therapy and associated improvement in clinical outcome: the MADIT-CRT (multicenter automatic defibrillator implantation trial with cardiac resynchronization therapy) study. J Am Coll Cardiol. 2012;59(25):2366-73.

42. Shanks M, Delgado V, Ng AC, Auger D, Mooyaart EA, Bertini M, Marsan NA, van Bommel RJ, Holman ER, Poldermans D, et al. Clinical and echocardiographic predictors of nonresponse to cardiac resynchronization therapy. Am Heart J. 2011;161(3):552-7.

\section{Publisher's Note}

Springer Nature remains neutral with regard to jurisdictional claims in published maps and institutional affiliations.

\section{Ready to submit your research? Choose BMC and benefit from:}

- fast, convenient online submission

- thorough peer review by experienced researchers in your field

- rapid publication on acceptance

- support for research data, including large and complex data types

- gold Open Access which fosters wider collaboration and increased citations

- maximum visibility for your research: over $100 \mathrm{M}$ website views per year

At BMC, research is always in progress.

Learn more biomedcentral.com/submissions 